\title{
Microscopy studies in support of OSL dating of mortars of historical buildings
}

\author{
J. Sanjurjo-Sanchéz*, C. Alves** and D. Teixeira** \\ *Instituto Universitario de Xeoloxía “Isidro Parga Pondal”, Universidade da Coruña/Edificio Servizos Centrais \\ de Investigación, Universidade da Coruña, Campus de Elviña, 15071 A Coruña, Spain. \\ **Centro de Investigação Geológica, Ordenamento e Valorização de Recursos, Universidade do Minho, Campus \\ de Gualtar, 4710-057 Braga, Portugal
}

There are several problems regarding the dating of the works in the historical buildings (see a review in [1]). Mortars are a potential material for dating of the built environment works, being ubiquitous and not reusable. Optical stimulated luminescence (OSL) dating can be applied to mortars with and without lime and considering the age interval of mortars from thousands of years up to a few decades [1]. OSL dating is based on measuring the accumulated luminescence signal of aliquots (of one or more mineral grains) of constituents from the mortars, resulting from the absorbed dose of surrounding radioactivity (at a constant dose rate), considering contributions both from environment and the radioactive phases of the mortars.

In this abstract is considered the relevance of microscopy studies as support for the preparation of samples for dating and the precise age calculations.

Microscopy studies can allow identifying samples that cannot be dated due to lack of enough grains of suitable phases as is illustrated in Figure 1a. It is also possible to assess the presence of datable phases. Usually quartz and potassium $(\mathrm{K})$ feldspar are used for dating (phases that can be easily distinguished by scanning electron microscopy and generally by polarizing optical microscopy). For dating, the OSL signal of such datable phases of a mortar must have been bleached before the mortar manufacture and settling, typically by daylight exposure of such minerals. Quartz grains have an easy to bleach signal. K-feldspars grains have a significant internal dose making them less susceptible to environmental variations but they present signal anomalous fading and the luminescence signal is harder to bleach than in quartz grains. However, according to [2], the effect of anomalous fading in K-feldspar may be negligible for samples younger than 100 years and there also some proposals for overcoming signal fading [3-4] and the combination of measurements on K-feldspars and quartz [5]. On the preparation of the sample, microscopy studies can assess the risk of contamination by other phases and, in analogy with what is done in mining studies, define a liberation size that relates to the obtainment of monomineral aliquots. It can also contribute to the identification of the presence of different grainsize fractions of the phases to use in dating (see example in Figure 1b), information that can be used for comparative studies of dose in the different grainsize fractions, such as isochron measurement procedures [3]. One of the main issues for dating is the assessment of the radioactive dose rate that affected the mortar constituents related to the distribution of the contents of $\mathrm{U}, \mathrm{Th}, \mathrm{Rb}$ and $\mathrm{K}$ that can occur disperse through the sample or concentrated on some grains. Most OSL studies on sediments relate K content to K-feldspar occurrences. However, in some mortars there could be an important presence of K-micas such as muscovite and the biotite series (see Figure $1 \mathrm{~b}, \mathrm{c})$ that have a lower $\mathrm{K}$ content and a different morphology. The presence of these mica grains has also been considered as potentially disturbing of the signal measurements and procedures for its removal have been proposed [6]. The grainsize distributions of radioactive grains and dated grains can also affect the way the radioactive dose affect the measured dose given that the same amount of $\mathrm{K}$ could be distributed in grains with different volume and hence different relation area/mass. Additionally, K-bearing phases can have contents of other radioactive elements affecting the beta dose [7] as is illustrated by Figure 1c showing the presence of halos resulting from radioactive decay of inclusions in biotite crystals. While in general it is admitted that quartz grains had a zero internal dose, the presence of inclusions such as rutile (that can be assessed by optical microscopy) can endanger this assumption. Microscopy studies can also be used to assess precipitation and dissolution process that occur after the preparation of the mortar and that can affect the beta dose for the grains (see Figure 1d). Finally, microscopy studies can be used after dose estimates and can help solve problems that have baffled researchers such as low content of feldspar separations [8]. In the case of mortar samples, for which can be 
obtained representative sections, the previous considerations show that petrographic models can help in the definition of spatial models for dose rate modelling and the establishment of appropriated age models.

\section{References}

1. Sanjurjo-Sánchez J., Brick and Mortar Research, Novapublishers, 171-194, 2012.

2. Li B. et al., Quaternary Geochronology, 2:23-28, 2007.

3. Li B. et al., J. Geophys. Res., 113:F02026, 2008.

4. Li B. and Li S-H., Quaternary Geochronology, 6:468-479, 2011.

5. Vogel J.C. et al., J Archaeol. Sci. 26:729-733, 1999.

6. Kortekaas M. and Murray A.S., Ancient TL., 23:43-46, 2005.

7. Zhao H. and Li S-H., Radiation Measurements, 40:84-93, 2005.

8. Li B. et al., Radiation Measurements, 42:1315-1327, 2007.

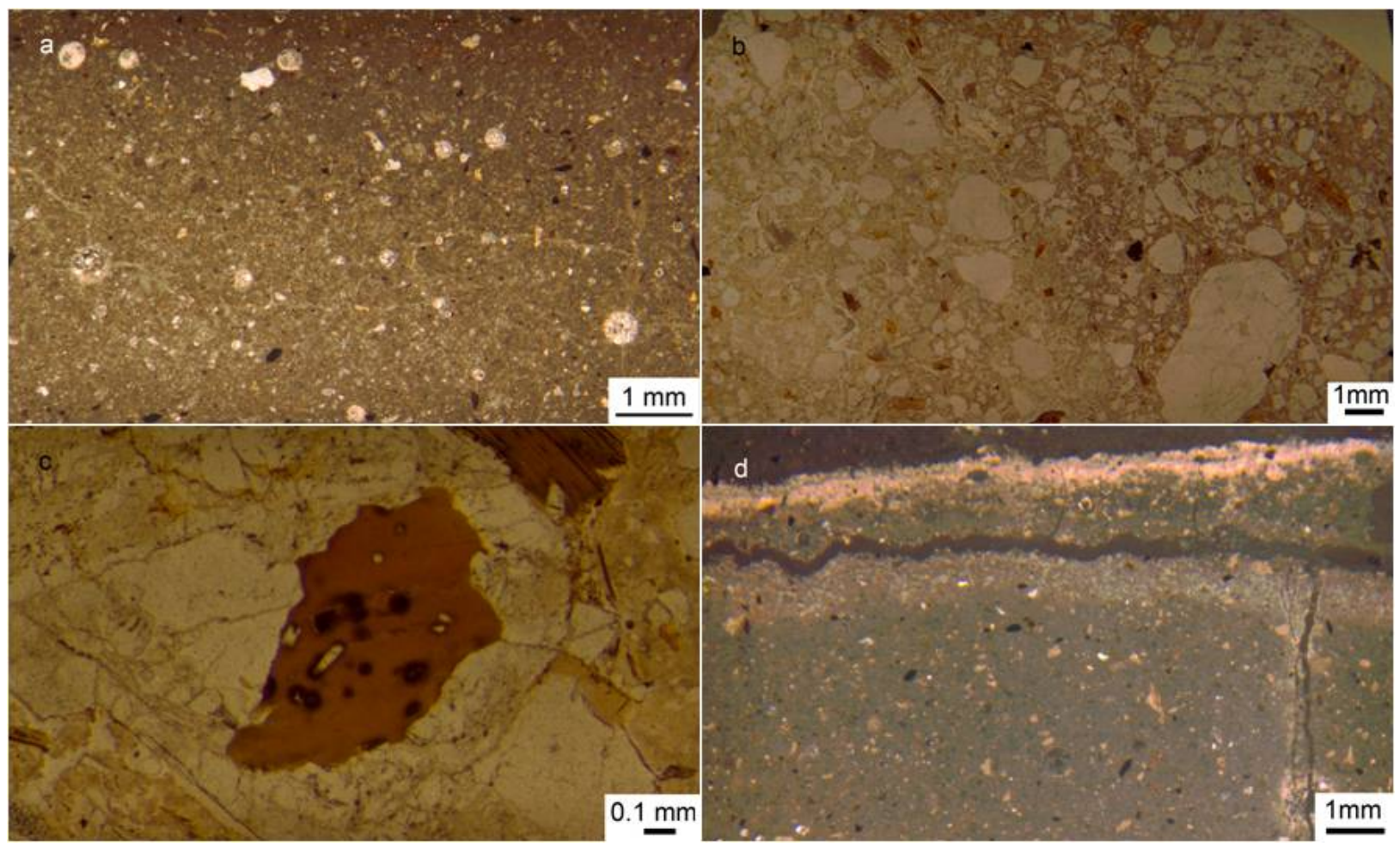

Figure 1. Polarizing optical microscopy observations relevant to dating of mortars: a) scarcity of grains for dating; b) grainsize heterogeneity and presence of biotite (brownish grains); c) biotite grains with pleochroic halos (radioactive decay from inclusions); d) calcite neoformations at surface and in fissures.

Support from Portuguese-Spanish collaboration Project "Ação Integrada E-141/10" (Fundação das Universidades Portuguesas)/“Acción Integrada PT2009-0077” (Ministerio de Ciencia e Innovación) and the Fundação para a Ciência e Tecnologia (pluriannual funding program for research units, PEstOE/CTE/UI0697/2011, Portuguese funds). 